\title{
Direito, \\ Teoria do Direito e Direito Penal
}

\section{Roberto Lyra Filho Escritor e professor universitário (UnB)}

1. Entre a Teoria Geral do Direito, em sua tentativa de elaborar os esquemas conceptuais necessários para as operações da Ciência Jurídica, e o Direito Penal, como disciplina especial, ainda se manifesta uma espécie de décalage, seja decorrente da falta de informação dos criminalistas, no que tange ao avanço da Teoria Geral, seja pela adaptação apressada do que esta última pôde construir com assento no terreno do Direito Privado. ${ }^{1}$

Por outro lado, os dados, por assim dizer, clássicos, a respeito da noção de norma jurídica, suas assim chamadas "divisões", sua estrutura conservam um desimpedido trânsito até nas obras mais recentes de algumas figuras representativas e em quase todas as de menor porte, fazendo caso omisso da produção já considerável das análises teóricas gerais, sob os pontos de vista lógico e ontológico. ${ }^{2}$ A Teoria Geral do Direito Privado e até, mais modernamente, a Teoria Geral do Processo estão, sem dúvida, mais desenvolvidas do que sua contraparte, tão pouco cultivada, a Teoria Geral do Direito Penal.

2. Tal situação perturba a formulação das chamadas regras de direito, isto é, as proposições em que se aglutinam os resultados da análise técnico-jurídica, na construção dos diferentes planos desentranhados do ordenamento ou conjunto de normas vigentes. Veja-se, por exemplo, a dificuldade que se apresenta à ocasião em que se pretende fixar a peculiaridade da norma penal, o que pode, sob algum aspecto, distinguí-la das demais normas jurídicas. Aliás, é comum aparecerem, nessa 
perspectiva, as posições que confundem duas coisas distintas: a questão da chamada autonomia do Direito Penal e a questão da.peculiaridade da norma penal, daquilo que há de permitir o recorte seguro do terreno propriamente jurídico penal na espécie de comunhão pro indiviso do ordenamento global.

3. Os criminalistas ainda tratam, com ênfase e, em geral, opiniões divididas, da questão da autonomia da norma penal, gastando tempo na discussão em que se pergunta se esta última se limita a reforçar as preceituações dos demais campos do direito ou se tem preceituações próprias.

As relações entre os diferentes ramos do direito e, mesmo, a não-contradição entre setores que pertencem a um mesmo ordenamento não impedem que o elenco de normas jurídicopenais estabeleçam, para seus próprios fins, direitos e deveres peculiares. ROBERTO LYRA lembra, por exemplo, que o art. 135 do Código Penal de 1940 é "privativo" do Direito Penal. (3) Aliás, acessoriamente, muitos conceitos e até institutos pertencentes a outros ramos do direito ganham disciplina autônoma. Note-se, quanto ao Direito Administrativo, o que se entende por funcionário público, em comparação com o alargamento que a este conceito dá a esfera penal; ou, no que tange ao Direito Civil, a transmutação da semântica jurídica, no que se refere a coisa móvel, casa, domicílio e assim por diante.

4. Uma coisa é, porém, reconhecer que o Direito Penal é visceralmente constitutivo (como qualquer outro) e, não, meramente sancionatório; e coisa muito diversa é atribuir ao preceito penal uma natureza, uma essência, diversa da que revelam as demais normas jurídicas. Nenhuma ilicitude é, em si, penal, de tal maneira que, ao passar à esfera da disciplina jurídica, recaia eo ipso no campo penal. Muitas condutas, noutros tempos ou lugares, enquadradas no âmbito penal, já passaram para o terreno civil ou mesmo nem se podem ver mais no elenco das infrações à disciplina privada ou à administrativa. De resto, o contrário também ocorre e, ultimamente, com desusada freqüência, quando o legislador se deixa empolgar pela idéia, aliás falsa, de que a cominação de sanções penais reforçará as preceituações, pela maior força intimidatória que elas representariam. Isto contrasta com duas ordens de direções evolutivas: a primeira consistindo no abandono da concepção intimidativa e repressiva do Direito Penal (cujo declínio, no pensamento e nas instituições mais avançadas, é evidente); a segunda apre- 
sentando-se através da verificação criminológica de que a intimidação é ilusória, pois, na presença dum potencial criminógino reforçado, a ameaça penal redobrada contribui para aumentar a própria tensão que se visa a subjugar.

A ilicitude civil ou penal é categoria puramente empírica, sujeita às oscilações histórico-culturais, sem qualquer delineamento teórico a priori.

5. Se, portanto, em que pese a autonomia constitutiva das preceituações penais, não há distinção ontológica, quanto ao que constituiria matéria de incriminação e o que recairia no âmbito de outros ramos do direito para configurar infrações de ordem civil ou administrativa, o recurso válido pareceria ser o exame de uma distinção mediante a peculiaridade das sanções. A sanção criminal seria, então, o critério distintivo.

É o que já sustentava, entre outros, GRISPIGNI, sem que isto deixasse de manifestar, entretanto, certas dificuldades especiais.

Para chegar à defesa de sua posição, que coincide com muitas respeitáveis opiniões, o mestre italiano dividia as sanções em executivas e punitivas. As primeiras, que coincidiriam com a prestação que é objeto do preceito (o dever jurídico), abrangeriam o impedimento da ação contrária ao preceito, o constrangimento ao cumprimento do preceito, a reposição no statu quo ante ou o ressarcimento, com prestação de um equivalente. No primeiro caso (impedimento da ação contrária ao preceito), não haveria, aliás, propriamente uma sanção, de vez que a não-prestação seria evitada. Nas sanções punitivas, por outro lado, a execução efetiva do preceito não se caracteriza, nem direta, nem indiretamente (por algum ressarcimento, de equivalência, aliás, puramente convencional). As sanções punitivas, segundo GRISPIGNI, seriam como que reafirmações simbólicas do preceito.

Ainda segundo GRISPIGNI, nas sanções punitivas entram em linha de conta, mais acentuadamente, as causas psíquicas da infração, isto é, o enlace da não-prestação e da sanção vincula-se ao elemento subjetivo, antes que à pura e objetiva realização ou não realização da conduta. Dentre as sanções punitivas, GRISPIGNI distingue as administrativas e as penais - o que, desde logo, em muito atenua, se não descaracteriza, a 
ênfase subjetiva, que pode estar presente no Direito Penal da culpa, mas não é elemento essencial ou, mesmo, fatalmente predominante no âmbito administrativo e ainda sofre os golpes, no próprio Direito Penal, de uma acentuada quota de infrações que se armam sob a égide da responsabilidade objetiva.

Por outro lado, segundo GRISPIGNI, as sanções criminais se apartam das administrativas, enquanto aquelas, diversamente destas, são impostas por um órgão da jurisdição. Observase que esta distinção só adquire relevo no âmbito da separação de poderes, sem esquecer as interferências funcionais que dão a poderes diversos atribuições de outros, como os aspectos administrativos da atuação judiciária, os aspectos judiciários da atuação de órgão do poder legislativo e, até, conforme o ordenamento, a presença de atribuições legislativas e até judiciárias em órgãos executivos. De qualquer sorte, a separação de poderes, inerente ao que GRISPIGNI chama o Estado Moderno, depende de que por tal nome se designe um Rechtsstaat visceralmente liberal, o que é muito simpático, mas não corresponde sempre à realidade da vida do direito contemporâneo.

Sob outro ângulo, cumpre lembrar que há todo um sabor clássico nessas elucubrações, pois a ênfase punitiva mais uma vez contrasta com a índole e a teleologia tutelares de muitos institutos penais, se não com todo o seu predominante endereço contemporâneo, desde a Scuola Positiva à Défense Sociale Nouvelle. (4) O sistema de medidas de segurança, por exemplo, cria dificuldades insuperáveis para um enquadramento como "sanções punitivas", em que pese a diminuição de um ou mais bens jurídicos. Resolver a questão, apelando para o artifício de designá-las como formas do poder coativo do Estado não parece resolver satisfatoriamente a questão. Vejam-se, por exemplo, as interdições, que aparecem no campo do Direito Penal, como no do Administrativo e até do Civil: a adotar-se o esquema, como elemento de lógica jurídica, chegaríamos à conclusão de que há "sanções criminais" de Direito Administrativo e até de Direito Civil... Há "sanções punitivas" civis aplicáveis jurisdicionalmente (basta lembrar o art. 395 do Código Civil, por exemplo).

6. Seria possivel ver, de autor a autor, quão artificiais se apresentam os critérios distintivos, ainda que isso conduzisse à conclusão, à primeira vista assustadora, de que não há uma separação radical entre os diferentes setores do ordenamento 
jurídico e que o Direito Penal (que alguns preferem chamar criminal, justamente em deferência ao colapso do ímpeto punitivo, repressivo, nas melhores direções evolutivas) não é mais do que um âmbito cujo recorte depende do tumulto das emergências históricas e dos acidentes na vida do direito.

O propósito desta nota, porém, é mais profundo. Ela pretende insinuar que, para além da décalage entre a Teoria Geral do Direito e a Teoria Geral do Direito Penal, há outro desajuste, entre as malhas duma pseudológica jurídica o espectro duma idéias de Estado e legislação e uma necessária revisão do conceito de Direito mesmo, segundo as direções do pensamento contemporâneo.

O problema teria que ser retomado da capo, sob pena (a expressão cai com certa ironia...) de se ver, sempre, insinuar entre as malhas duma pseudo-lógica jurídica o espectro duma ontologia jurídica mutiladora, desatualizada e, afinal, contrastante com o que o Direito (em sua integridade maiúscula) realmente é.

Foi todo esse itinerário que levou o autor destas linhas a esboçar uma construção, partindo dos conceitos de Homem, Ética e Direito, para chegar à desobstrução dos caminhos de um conceito de crime, a que a Teoria Geral do Direito, em sentido clássico, não poderia trazer elucidação. Daí todo o sentido de uma Criminologia Dialética, ${ }^{(5)}$ em que o mestre de Bolonha, Prof. LUIGI BAGOLINI quis ver, generosamente, uma "contribuição pessoal, original" e em que o Prof. DENIS SZABO, diretor do Centro Internacional de Criminologia Comparada, com igual munificência, reconheceu um adminículo brasileiro a debate de porte internacional.

A esperança, que agora se formula, é a de que, entre nós, se possam desenvolver as investigações iniciadas, por um mais amplo debate dos fundamentos filosóficos do Direito Penal e da Criminologia, que se vêm desenvolvendo na Universidade de Brasília.(6) Esse esforço de manter a inquietação e a vida intelectual livre parece ao autor desta nota o traço de continuidade da própria UnB, através de todas as suas crises de crescimento, absorvendo contradições periféricas, para coligar-se à inspiração renovadora, ainda presente no ano do seu décimo aniversário. 


\section{NOTAS}

1) ROBERTO LYRA FILHO, Curso de Teoria Geral do Direito Penal e Criminologia, Brasilia, UnB (edição mimeografada), 1965, passim.

2) MIGUEL REALE, O Direito como Experiência, São Paulo, Saraiva, 1968, p. 227 e segs.

3) ROBERTO LYRA, Introdução ao Estudo do Direito Criminal, Rio, Editora Nacional de Direito, 1946, p. 197.

4) Quanto às ligações entre a Scuola Positiva e a Défense Sociale Nouvelle, ver MARC ANCEL, La Défense Sociale Nouvelle, Paris, Cujas, 1966, passim. O avanço, para além dessa acomodação neo-positivista (no sentido jurídico-penal), é demarcado, pelo autor desta nota, em seus escritos: ver e. g., Criminologia Dialética em Ação, in Noticia do Direito Brasileiro - 1971, Brasília, Gráfica do Senado, 1972.

5) ROBERTO LYRA FILHO, Criminologia Dialética, Rio, Borsol, 1972 passim.

6) Ver ROBERTO LYRA FILHO, Plano de Curso de Especialização em Sociologia do Crime (Pós-graduação), Brasília, Edição mimeografada, 1972, passim. Sobre esse plano, assim se manifesta no Centro Internacional de Criminologia Comparada, por seu diretor, Prof. DENIS SZABO: "O plano me parece bem estruturado e perfeitamente concebido para desenvolver pesquisas criminológicas na moldura do ensino das ciências sociais. A ênfase numa sólida formação nessas disciplinas é, ali, posta com avançada especialização nos métodos de pesquisa. Acho esses desenvolvimentos extremamente desejáveis, num país que deverá enfrentar necessidades crescentes no terreno do estudo da aberração (déviance) e das diferentes formas de criminalidade" (ofício de 10 de novembro de 1971). 